\title{
Choices of Post-graduation Medical specialization among final year medical students, interns and medical officers working in different hospitals in Pokhara, Nepal
}

\author{
${\text { Karuna Acharya*1(D), Ishwar Sharma Kandel }{ }^{2} \text {, Abhishek Shrestha1 }}^{1}$ \\ Department of General Practice and Emergency medicine, ${ }^{2}$ Department of Orthopaedics, \\ Gandaki Medical College Teaching Hospital, Pokhara, Nepal.
}

\begin{abstract}
Background: The intricate decision to pursue finally one speciality following post bachelor's medical degree is affected by many factors in Nepal. The aim of the study was to elucidate the preference of specialty among final year medical students, interns and medical officers currently working in Pokhara city of Nepal. Methods: Observational crosssectional survey, conducted from $1^{\text {st }}$ Feb to $30^{\text {th }}$ April, 2020. 127 participants including doctors working in private and government hospitals of Pokhara, Nepal. Structured questionnaire was prepared and distributed to participants. Data were entered, validated in Microsoft Excel 2017 and analyzed in SPSS, version 25. Chi-squared and t-tests were applied for categorical and continuous variables respectively to test the statistical significance at $95 \%$ confidence level. Results: Of the total respondents, 30.46\% reported clinical subjects as their preferences, followed by any clinical and basic subjects (20.31\%). For clinical, Internal medicine was preferred by $15.6 \%$, Surgery by $9.3 \%$, Dermatology by $6.25 \%$, Orthopedics by $4.68 \%$, Pediatrics, Health care management, Psychiatry, Otorhinolaryngology, Gynecology and Ophthalmology were reported by $3.9 \%, 2.3 \%, 1.5 \%$ and rest $0.7 \%$, respectively. $64 \%$ of the participants chose their speciality based on their keen interest, and while $17.9 \%, 12.5 \%$ and $3.1 \%$ closed due to pressure from family members, experience while working and anticipation of good quality of life respectively. Conclusion: High proportion of the respondents' preferred clinical speciality. Most opted clinical speciality was Internal Medicine. This may lead to saturation in those areas of specialization and as a result leave the population underserved in other important areas basic science involving clinical teaching and learning.
\end{abstract}

Keywords: Medical speciality, career choices, Pokhara.

\section{Correspondence to:}

Dr. Karuna Acharya

Associate Professor, Department of General Practice and Emergency Medicine, Gandaki Medical College and Teaching Hospital, Pokhara, Nepal

Email: karunakandel@gmail.com

Submitted: July 21, 2020

Accepted: December 2, 2020

To cite: Acharya K, Kandel IS, Shrestha A. Choices of Post-graduation Medical specialization among final year medical students, interns and medical officers working in different hospitals in Pokhara, Nepal. JGMC Nepal. 2020;13(2):183-7.

DOI: $10.3126 /$ jgmcn.v13i2.31034

\section{INTRODUCTION}

Career choices in medical field likely to change overtime as the students understand better as they move forth from first year to last year internship period of medical schooling. While on their medical officer/house officer tenure, the doctors usually plan for the career ahead they are likely to follow. For some it is a straightforward decision whereas for others it is a dilemma and a tough decision to choose what path to pursue. ${ }^{1}$ In the neighboring country, a study quoted that a majority of students preferred to choose a postgraduate career in medicine and Pediatrics followed by Surgery. ${ }^{2}$ Usually after MBBS a fresh graduate has multiple different paths and careers to choose ranging from clinical sciences, applied medical sciences, pharmaceutical, information technology and other non-clinical fields. ${ }^{3}$

Medical graduate's choice of specialty also relies heavily on the field that interests them the most during their internship rotation period to various departments. Around the globe we see 
different trends for medical students choosing a particular set of career choices after completing their bachelor degree with various reasons pertaining to their decisions. ${ }^{4}$

Most medical schools have limited residency programs to satisfy the postgraduate career preference, limited role on current and future possibilities (enhancing participation for collective and individual learning) including in providing career and social orientations to medical students. ${ }^{5-7}$ The needs of the medical graduates do not seem to have been addressed.

In most cases, it is observed that students never wishes to take up basic science speciality, as their knowledge and skills become limited to teaching and learning activities and is very restricted. ${ }^{8}$ There is need to find out what motivates the students to take up certain speciality of their choice so that the balance in medical doctors among various specialties is maintained. Research studies conducted in India observed that educational loans and life style factors may be the determining factors for the choice of specialty by the students. ${ }^{9}$ It has been observed that choices of particular specialties in medical field vary from region to region. Little research has been done in Nepal to explore the demographics of specialty choices. These types of studies can be helpful in career counseling and policymaking. In Nepal, all medical schools offer a five year program, with basic health sciences as the primary focus during the first two years, with gradually increasing exposure to clinical rotations over the next three years, followed by a one year compulsory internship in a teaching hospital. Some private medical institutions are following a problem-based learning system, whereas the government medical institutions follow a conventional lecture-based curriculum. The objective of this research was to determine the choices of Post-graduation Medical specialization among final year medical students, intern and medical officer working in different hospitals in Pokhara, Nepal.

\section{METHODS}

\section{Study design and study setting}

An observational cross-sectional survey study was conducted over period of three months from $1^{\text {st }}$ February to $31^{\text {st }}$ April 2020. The study was conducted in three Private hospitals, two medical colleges and one government hospital of Pokhara Metropolitan, Kaski.

\section{Study Sample}

Final year students, Interns and Medical officer doctors were included in this study. Students till $4^{\text {th }}$ year were excluded because of limited exposure to clinical work in the early years of medical career.

\section{Data collection tool and techniques}

The authors developed a self-administered questionnaire in English language, which is the not an official language of Nepal but is convenient for communication as English is widely spoken and understandable language among medical students, as well as medical curriculum is in English language in Nepal. The participants were recruited randomly and those who were interested to participate were enrolled from different hospitals, including government, private sectors and medical colleges. This was done voluntarily. An anonymous, paper-based questionnaire was used to collect data which include demographic variables, preferred subject or speciality, factors determining the preference, possible time frame of entering the post-graduate program and choice of country preference. In total we had 22 respondents working in government hospitals, 68 respondents from private hospitals, 17 from Gandaki Medical College and 20 were final year student's and interns. The questionnaire was anonymous to ensure the confidentiality of the data.

\section{Statistical analysis}

A structured questionnaire was prepared and distributed to participants and was completed by them. Data were entered and validated in Microsoft Excel 2017. Data analysis was performed in SPSS, version 25. A self-reported choice of different clinical and non-clinical specialties was the defined outcome. Chi-squared and t-tests were applied for categorical and continuous variables respectively to test the statistical significance at 95\%confidence level.

\section{RESULTS}

The response rate was 100 percent with 127 doctors/ undergraduates completing and returning the questionnaire form. There was predominance of male doctors (66/51.9\%) with no statistically significant difference with $\mathrm{p}=0.65$ (table 1). The participants were between the ages 21-35 years, with majority from 21 to 26 years age (80.3\%). Majority of the participants were either undergraduates or MBBS graduates found to have been studied from personal financial source (93.7\%). Forty-nine and 44 out of 127 , planned to enter the postgraduate program within one and two year, respectively, with almost equal distribution in males and females. Most of the participants were working in private hospitals (68 out of $127,53.5 \%$ ), followed by government hospitals (22 out of $127,17.3 \%$ ). Eighty four participants $66.1 \%$, (male: 47 , female:37) would choose medical speciality because of keen interest in that subjects(table 3), Out of 16, 11 were females who chose specialty due to work experience whereas 18 females out of 24 respondents were flexible for any subjects. There were only three participants who would choose 
specialty for family wish (table 3). About 25.2\% (32/127) of the participants wish to study post-graduation in foreign countries whereas majority of participants preferred to study in home country Nepal which was dominated by $70.8 \%$ (table 4). Hospital based specialty were the most attractive, majority of participants chose clinical specialty 100 vs 27 (table 5), age 24 to 26 were among the most interested in clinical subjects. Most opted clinical specialty was Internal Medicine $19.6 \%$ followed by Surgery, Pediatrics and so on (table 2).

The study compared the different variable factors that affect the choice of specialty. Age between 24 to 26 years demonstrated highest interests in clinical specialty (Table 5). Thirty four out of 49 and 28 out of 44 participants plan to enter post-graduate program within one and two years respectively. All the 22, participants working in government hospital interested in one particular specialty. The main reason to choose one particular specialty was keen interest $(55 / 73,75.3 \%)$ when compared to work experience.

Table-1: Characteristics of the study population

\begin{tabular}{ccc}
\hline Characteristics & Number & Percentage \\
Age Distribution & & \\
$21-23$ years & 31 & 24.4 \\
$24-26$ years & 71 & 55.9 \\
$27-29$ years & 19 & 14.9 \\
$>30$ years & 6 & 4.7 \\
Sex & & \\
Male & 66 & 52 \\
Female & 61 & 48 \\
Type of under graduation & & \\
funding & & \\
Partial Scholarship & 3 & 2.36 \\
It is Full Scholarship & 5 & 3.93 \\
Full Payment & 119 & 93.7 \\
Current work station and & & \\
affiliation & & 17.3 \\
Government Hospital & 22 & 53.5 \\
Private Hospital & 68 & 13.3 \\
Medical Colleges & 17 & 15.7 \\
Undergraduates & 20 & \\
\hline
\end{tabular}

Table 2: Different medical specialties preferred by study participants

\begin{tabular}{ccccc}
\hline Medical speciality preferred by study & \multicolumn{2}{c}{ Male $(\mathbf{n}=\mathbf{6 1})$} & \multicolumn{2}{c}{ Female $(\mathbf{n}=\mathbf{6 6})$} \\
Population & $\mathbf{n}$ & $\mathbf{\%}$ & $\mathbf{N}$ & $\%$ \\
Any clinical subject & 7 & 11.4 & 20 & 30.3 \\
Internal Medicine & 12 & 19.6 & 6 & 9.1 \\
Pediatrics & 4 & 6.5 & 6 & 9.1 \\
Surgery & 10 & 16.3 & 2 & 3.0 \\
Otorhinolaryngology & 1 & 1.6 & 0 & 0.0 \\
OBGYN & 1 & 1.6 & 4 & 6.1 \\
Orthopedics & 4 & 6.5 & 2 & 3.0
\end{tabular}

\begin{tabular}{ccccc} 
Psychiatry & 2 & 3.2 & 0 & 0.0 \\
Dermatology & 2 & 3.2 & 6 & 9.1 \\
General Practice and Emergency Med & 0 & 0 & 2 & 3.0 \\
Public Health & 1 & 1.6 & 0 & 0.0 \\
Neurosurgery & 1 & 1.6 & 0 & 0.0 \\
Ophthalmology & 1 & 1.6 & 0 & 0.0 \\
Pathology & 0 & 0 & 0 & 0.0 \\
Health care management & 2 & 3.2 & 1 & 1.5 \\
Microbiology & 0 & 0 & 1 & 1.5 \\
Not decided & 1 & 1.6 & 1 & 1.5 \\
Any subjects including basic science & 12 & 19.6 & 15 & 22.7 \\
\hline
\end{tabular}

Table 3: Reasons of subject preferences

\begin{tabular}{cccccc}
\hline Characteristics & \multicolumn{4}{c}{ Sex of the respondents } & P value \\
Reason for opting particular & Male $(\mathbf{n}=\mathbf{6 1})$ & Female $(\mathbf{n}=\mathbf{6 6})$ & \\
speciality & N & \% & $\mathbf{n}$ & $\%$ & \\
Keen interest & 47 & 77.1 & 37 & 56.1 & 0.04 \\
Work experience & 5 & 8.1 & 11 & 16.6 & 0.65 \\
Flexible to choose & 6 & 9.8 & 18 & 27.27 & 0.38 \\
Family wish & 3 & 5 & 0 & 0 & \\
\hline
\end{tabular}

Table 4: Preferred country for PG study

\begin{tabular}{ccc}
\hline Preferred country for PG study & Number & Percentage \\
Nepal & 90 & 70.8 \\
Abroad & 32 & 25.2 \\
Anywhere & 5 & 3.93 \\
\hline
\end{tabular}

Table 5: Characteristics of the study population associated with medical specialty preference

\begin{tabular}{|c|c|c|c|c|}
\hline \multirow{2}{*}{ Characteristics } & \multicolumn{2}{|c|}{ Subject preference } & \multirow{2}{*}{$\begin{array}{l}\text { Chi-square } \\
\text { value }\end{array}$} & \multirow[t]{2}{*}{ P value } \\
\hline & $\begin{array}{c}\text { Clinical } \\
\text { n (\%) }\end{array}$ & $\begin{array}{c}\text { Others } \\
\mathrm{n}(\%)\end{array}$ & & \\
\hline \multicolumn{5}{|l|}{ Age (in years) } \\
\hline 21-23 & $22(71)$ & $9(29)$ & 4.501 & 0.033 \\
\hline $24-26$ & $54(76)$ & $17(24)$ & 14.880 & $<0.001$ \\
\hline$>27$ & $24(96)$ & $1(4)$ & 11 & $<0.001$ \\
\hline \multicolumn{5}{|l|}{ Sex } \\
\hline Male & $49(80)$ & $12(20)$ & 15.73 & $<0.001$ \\
\hline Female & $51(77)$ & $15(23)$ & & \\
\hline \multicolumn{5}{|l|}{$\begin{array}{l}\text { Type of under graduation } \\
\text { funding }\end{array}$} \\
\hline Partial Scholarship & $3(100)$ & 0 & & \\
\hline Full scholarship & $4(80)$ & $1(20)$ & 1.059 & 0.3 \\
\hline Full payment & $93(78)$ & $26(22)$ & 28.064 & $<0.001$ \\
\hline \multicolumn{5}{|l|}{$\begin{array}{c}\text { Current work station and } \\
\text { affiliation }\end{array}$} \\
\hline $\begin{array}{l}\text { Undergraduate and } \\
\text { internship }\end{array}$ & $15(75)$ & $5(25)$ & 3.8 & 0.05 \\
\hline Medical collage & $12(70)$ & $5(30)$ & 2.185 & 0.139 \\
\hline Private hospital & $51(75)$ & $17(25)$ & 13.4 & $<0.001$ \\
\hline Government hospital & $22(100)$ & 0 & & \\
\hline
\end{tabular}

\section{DISCUSSION}

Our study surveyed the choices in specialization and factors affecting the choices among doctors working in tertiary 
centers, teaching hospitals and government hospitals. Those students who cannot secure seats in scholarship exam have no other choice than to take up MBBS program in full payment in private medical colleges. That can be the reason; the number of private medical college across the globe is on the rise. Because of high demand of medical seats private medical college takes heavy fees in MBBS. Due to high fee structure for MBBS program which can be a huge burden to the family, the medical students develop eagerness to earn money to pay back their dues and uplift the family's financial state. ${ }^{10-12}$ which becomes a matter of preference for clinical science subjects in postgraduate and earn more through private practice and repay back the loan for which they are indebted. ${ }^{13}$ We did not collect the data on merit position of the participants. We did not examine the reasons for not preferring a particular field. But some important aspect of decision to choose medical specialty was unleashed in this study.

Reduced working hours means a better quality of life. This was the most important reason for selecting medical and allied as a career choice. Most of the individuals choosing for Family medicine also had the same reason. ${ }^{1,14,16}$ In this study, we found only two female doctors opted General Practice/ Family medicine. But majority of the doctors would like to take post-graduate training in any clinical subjects $(21.2 \%)$ followed by medicine (14.1\%) and Surgery (9.4\%). Similarly, participants who graduated from private medical schools were more likely to choose one particular clinical specialty $56.3 \%$ of 119 . When considering the age determinants, age above 24 years respondents were more likely to choose one particular specialty rather than keeping options of any clinical or non-clinical speciality and age above 27 years showed more preference for one particular subject. In this study, $25.1 \%$ doctors prefer to go abroad for further study but the country of origin also is an important factor in selecting any given specialty, as the chances of an individual getting into highly competitive field such as Surgery and allied may be difficult in some countries such as USA and Canada. So their candidates tend to apply in the residency in specialties which are easier to get into. ${ }^{16,17}$ This study shows doctors prefer to get training in the medical speciality of their keen interest (43.3\% of 127), as $70.8 \%$ of 127 doctors prefer to study post-graduate in Nepal. There is a decline in the number of students to pursue a post-graduate career in basic science subjects in comparison to clinical subjects. So, in Nepal, Kathmandu University have started enrolling Bachelor of Dental Surgery graduated for MD in basic science subjects. However, in this study, $21.2 \%$ respondents want to study any clinical subjects, with same percentage of doctors opted any clinical or basic science subjects.
Here, in this research when it comes to choosing one particular specialty, 42 males predominate over 31 females. Similarly, females (20/27) were more liberal in choosing any clinical specialty. Study conducted by Subba et $\mathrm{al}^{18}$ showed that male medical students opt for Surgery and females opt for OBGYN and internal medicine which concurred with our study. Another study in India, observed male medical students choosing internal medicine and Surgery as their specialization, compared to female choosing OBG and Pediatrics. ${ }^{19}$ Doctors working in government hospital were more likely to enter post-graduate program in one or two year and more likely to choose one particular medical specialty compared to doctors working in private hospitals or medical colleges. With no surprise, undergraduates plan to enter post-graduate training in three to four year.

\section{Study limitations}

There were few limitations of this study. Since this is a crosssectional study with small sample size, it only gives small view of choices and the factors that influence the preference. The sample drawn from interns and from medical officer working in different instates of Pokhara and may not be generalizable to other provinces and countries. Participants were not scrutinized whether they were from rural or urban areas, lifestyle, and marital status and expected working hours and salary would affect the choice of with particular specialty.

\section{CONCLUSION}

Most respondents prefer to study clinical specialty followed by few respondents prefer for either clinical or basic medical science subjects, which ever they get. Doctors working in government hospital were more focused on choosing and entering specialty of their interest within one to two years. Majority of respondents preferred to pursue their postgraduate training in their home country Nepal. Similar studies with better knowledge of the demographics and need for medical specialties across Nepal is needed to determine educational direction and policy making. This capability will better prepare developing countries to meet their present and future medical needs.

\section{Funding:}

No any funding source.

\section{REFERENCES}

1. Pfarrwaller E, Sommer J, Chung C, Maisonneuve H, Nendaz M, Perron NJ, et al. Impact of interventions to increase the proportion of medical students choosing a primary care career; A systemic review. JGenInternMed. 2015;30(9):1349-58. DOI: 10.1007/ 
s11606-015-3372-9

2. Singh MK, Singh AK. What to do after MBBS? An Analysis of MBBS career aspiration and their determinants. Indian J Prev Soc Med. 2012;43(2):13440.

3. Hayes BW, Shakya R. Career choices and what influences Nepali medical students and young doctors: a cross-sectional study. Human Resources for Health. 2013;11:5. DOI: 10.1186/1478-4491-115PMID: 23394308.

4. Hurst SA. Eroding students' rural motivation: first do no harm? Swiss Med Wkly. 2014;144:w14020. DOI: 10.4414/smw.2014.14020 PMID: 25399015

5. ChenCBE,WassermannT,etal.AsurveyofsubSaharanAfricanmedicalschools.Human Resources for Health.2012;10:4. DOI: 10.1186/1478-4491-10-4 PMID: 22364206.

6. Mann KV. Theoretical perspectives in medical education: past experience and future possibilities. Med Educ. 2011;45:60-68. DOI: 10.1111/j.13652923.2010.03757.x PMID: 21155869.

7. Humlum MK, Kleinjans KJ, Nielsen HS. An Economic Analysis of Identity and Career Choice. IZA Discussion Paper No. 3120.2007. DOI: 10.1111/j.14657295.2009.00234.x

8. Elstein AS. On the origins and development of evidence-based medicine and medical decision making. Inflamm Res. 2004;53(Suppl2):S184-89. DOI: 10.1007/s00011-004-0357-2 PMID: 15338074.

9. Why do Doctors Make So Much Money? Available from: https://www.wisegeek.com/why-do-doctorsmake-so-much-money.htm [Accessed September 23,2020]

10. Sood R. Medical Education in India. Med Teach.2008;30:585-91. DOI: 10.1377/ hlthaff.27.3.w232

11. Morra DJ, Rehegr G, Ginsburg S. Medical students, money, and career selection: student's perception of financial factors and remuneration in family medicine. Fam Med. 2009;41:105-10. DOI: 10.22454/ FamMed.2019.772315

12. Adhikari RK. Privatization in Technical Education: The Case of Education of Health Professionals in Nepal. Reg Health Forum. 2006;101:59-64 DOI: 10.4103/1947-2714.128473

13. By wood Editorial Consultants. Building a health system for improving health in India. Report of the National Commission on Macroeconomics and Health. Ministry of Health and Family Welfare Government of India. In: Lal PG, editor. New Delhi: 2005. Pp. 92-131.

14. Kumar B. Family medicine: A Resident's Perspective. J Fam Med Primary Care. 2012;1:59-61. DOI: 10.4103/2249-4863.94455 PMID: 24479004.

15. Wright B, Scott I, Woloschuk W, Brenneis F. Career choice of new medical students at three Canadian universities: Family medicine versus speciality medicine. JAMC. JUIN. 2004;170(13):1920-24 DOI: 10.1503/cmaj.1031111 PMID: 15210640.

16. Takeda Y, Morio K, Snell L, Otaki J, Takahashi M, Takeda IK, et al. Characteristics profiles among students and junior doctors with specific career preferences. BMC Med Educ. 2013;13:125. DOI: 10.1186/1472-692013-125 PMID: 24028298

17. Newton DA, Grayson MS, Thompson LF. The variable influence of lifestyle and income on medical sudents' career speciality choices: Data from two U.S. Medical Schools 1998- 2004. Acad Med. 2005;80(9):809-14. DOI: $10.1097 / 00001888-200509000-00005$ PMID: 16123458

18. Subba SH, Binu VS, Kotian MS, Joseph N, Mahmood AB, Dixit N, et al. Future specialization interests among medical students in Southern India. Natl Med J India. 2012;25:226-29.

19. BhatS, D'souza L, Fernandez J. Factors influencing the career choices of medical graduates. J Clin Diagn Res. 2012;I-6:61-4. DOI: 10.18535/jmscr/v6i6.136 